\title{
Nursing English in Pakistan: Instructors' Perceptions of Language Curriculum
}

Adeel Khalid

\begin{abstract}
Nursing English in Pakistan is an important domain that comes under the ambit of ESP 'English for Specific Purposes'. English cogitates as a lingua franca and a cornerstone for success in any field. However, in ESL/ELT it is imperative to design a course that caters to the needs of the learners. Thereby this study attempts to evaluate the existing English for Nursing Purposes curriculum of $\mathrm{BScN}$ Programme prescribed by HEC/PNC to corroborate its relevancy and adequacy in preparing the musing professionals for their professional English language requirements using Stufflebeam's curriculum evaluation framework. This investigative study measures the level of existing linguistic (in)adequacy of the professional nurses pertaining to the specific roles they are required to perform so that their problematical areas could be identified systematically and subsequently reported with recommendations. A qualitative research approach has been used to measure the needs of the nurses. Tools like open-ended questionnaires and semi-structured interviews have been used to collect data from the sample sizes nursing heads and language instructors consecutively. The findings of the study divulge that the course is inadequate and yet relevant. It is recommended to review the English language curriculum considering the needs of the nurses for their work place that may improve the standards of nursing English in Pakistan.
\end{abstract}

Key words: Nursing English, perception, language curriculum.

\section{Introduction}

A bird's eye view of the broader spectrum of Pakistan's post-secondary education system today, one would see the bright prospects provided by both Higher Education Commission (HEC) and Technical Education and Vocational Training Authority (TEVTA) institutions for tertiary education. Each institution plays a significant role in developing informed and skillful human resource for national development. In line with this aspiration, the nursing as a profession in Pakistan is one of the focal fields of health care unit where there are bright prospects as well as opportunities at academic and professional fronts. Thereby if the nursing professionals have to move up at the ladder, it is imperative to have good grip and grasp over English language in all the four skills. English as a lingua franca of the world evidently maneuvers to rule every profession as a prevailing means of communication. Hence it proves cornerstone for the success in any field.

There have been ongoing debates on the issues of the low English language proficiency level in the students amongst academicians, the community as well as the industry which is the prospective employers of the future graduates. One of the crucial aspects that nursing students at 
medical institutes are lacking is having excellent proficiency in English. These students might be good in their subject matter but the same could not be said to English language. In 2006, a new curriculum for nursing education has been developed for the first time by Pakistan Nursing Council (PNC) in collaboration with the Higher Education Commission (HEC) that is a generic curriculum leading to a $\mathrm{BScN}$ degree for the country which is referred to as the HEC/PNC curriculum. The practical application of this curriculum will be standardization and quality assurance especially that of language in nursing education in Pakistan. Most of the English as Second Language (ESL) programmes in Pakistan do not cater to the potential needs of the learners both in their academic as well as professional settings. This is mainly because the prescribed English syllabi are not in accordance with the specific needs of the learners. In addition, the teachers are not properly trained to teach the English language. As a result, these professional institutions remain inadequate in equipping their students with the required linguistic and communicative competence.

There are debates on the discrepancy between the expectations and the needs of the field. Therefore, the debates still prolong as to why the Pakistani graduates are still facing problems of low proficiency level of English language that hinders their ability to communicate effectively and adapts to the needs of the employers. In addition, the English language lecturers in medical institutes have never shared their views on the EOP 'English for Occupational Purposes' syllabi. Questions for example whether the content of the ESP nursing English for Occupational Purposes module is insufficient to prepare the students for the work place or whether the language skills of the ESP English for Occupational Purposes syllabus is sufficient in addressing the actual problem faced by the students. Thus, the syllabus for the ESP Nursing English for Occupational Purposes course for the BScN Bachelor in Sciences Nursing Programme is chosen to gauge the scope of the course that is meeting the stated objectives as well as the needs of the employers and the industry.

A number of linguists such as Flowerdew and Peacock (2001) and Basturkmen (2006) laid emphasis on needs analysis as an insinuating point for devising syllabuses, courses, materials for specific audiences. Needs assessment could be defined as "the process of determining the needs for which the learner or group of learners required a language and arranging the needs accordingly to priorities ... [It] made use of both subjective and objective information" (Richards et al. 1992).

Munby (1978) stated that needs analysis could also help in evaluating an existing programme and if found deficient might help in establishing the need for introducing a change and what kind of change might appropriately match the needs of the learners and simultaneously be acceptable to teachers.

The classification of language and skills was used in determining and refining the context for the ESP course. This process was termed as needs analyses. This kind of needs analysis brought about the attitudes of the learners, instructors, donor agencies or employees of an organization towards introducing a needs-based English language course. Therefore, needs analysis had utilitarian purposes for altering, shaping, or reshaping the course according to the needs of the specific learners and demands of the specific situations in a systematic way. The first and foremost task of an ESP practitioner was to identify the needs of the learners and design a course around them.

$2 \quad$ Journal of NELTA, Vol 21 No. 1-2, $\quad$ December 2016 


\section{Objectives of the study}

This research carries the following objectives:

- To assess the relevancy and adequacy of the ESNP 'English for Nursing Purposes' course being taught in Nursing Programmes.

- To propose a standardized professional language programmes for nursing

This study aims to examine the needs of the nurses' workplace requirements and to evaluate the existing English languages courses taught at different institutions. It attempts to identify the significance and relevance of the English language course vis-à-vis the specific professional requirements of the nursing staff and their assigned academic and professional roles, they have to assume once they enter into practical field. This research carries the rationale of ESP 'English for Specific Purposes' in the context of ENP 'English for Nursing Purposes'.

\section{Research question}

The overarching research question is:

To what extent is the existing English Language Curriculum of BSCN at the Nursing Institutes in Pakistan successful in preparing the nurses for using English in their academic and professional settings?

\section{Research methodology}

The qualitative research paradigm is the technique of detailed analysis, in-depth narrative inquiry and investigation of the data that mainly contains words at a broader level (Ragin 1994, p. 91). This technique primarily seeks to amass information from an event, decision, institution, geographical location, issue or piece of legation (Silverman 2000:2).

Robinson (1991) suggests a number of different methods for conducting needs analysis. These include questionnaires, interviews, case studies, tests, authentic data collection (e.g. analyzing actual manuals, written assignments). According to West (1994), the most widely used methods are these studies, interviews and questionnaires.

\section{Semi-structured interviews}

In addition to the questionnaire, the third major data tool used in this study is semistructured interview. Patton (2002) described semi-structured interviews as a natural extension of participant observation, because they so often occur as part of ongoing participant observation fieldwork. He argued that they rely entirely on the spontaneous generation of questions in the natural flow of an interaction. There are no official and agreed-upon guidelines for how to conduct an unstructured interview. But in practice, many researchers comply with the steps listed below (Fontana \& Frey, 2005) when planning and conducting unstructured interviews.

There are various reasons for selecting semi-structured interviews as a method. It requires negotiation techniques and tactics to conduct an interview. The researcher takes a careful analysis of the possible political, legal, and bureaucratic barriers that may arise during the process of gaining access to the setting (Lofland, 2006).

The interview questions have been divided into these domains dealing with nursing English: in terms of their experience and qualification, need and importance of the 
English language skills for the nursing students, problematic areas, relevancy and adequacy of the course and lastly their suggestions to improve the standard of existing language program.

The first type aims to trace the professional experience of the instructors who are important stakeholders in transmitting English language skills to the students. The second type is related to the importance and need of the English language skills for the prospective nursing professionals. The third type is to identify the problematic areas of the students among the four basic skills. The fourth type of questions is related to the relevancy of the English language curriculum for nurses to equip them for their professions. The fifth part deals with that of adequacy facet of the existing curriculum taught to these nurses whether these are sufficient in catering to the needs of the learners. The last category is to take their insight on this issue in the light of their experience as it is the most important component of this method. It has been observed that usually teachers do not get enough say in the curriculum designing stage. Since they are aware of the ground realities and there are bright chances of getting the required data through this technique (Flowerdew \& Peacock: 2001).

The purposive sampling technique was used in this study. The research aimed to evaluate the English language courses taught at nursing institutes by investigating their linguistic needs required to perform the specific roles at their workplace, and effectiveness of the current English BScN curriculum (Dudley-Evans \& St.John, 1998). In order to investigate the above mentioned areas, the researcher decided to gather information from the instructors of
BScN English Language programme. Six language instructors took part in this study.

\section{Nursing education in Pakistan}

The following Nursing diplomas, degrees and training courses have been offered by Pakistani universities.

\section{Table 1: Nursing education in Pakistan}

$\begin{array}{ll}\text { BScN Bachelor in Sciences Nursing Generic } & 4 \text { Years } \\ \text { General Nursing \& Midwifery Training Course } & 3 \text { Years } \\ \text { Post RN B.Sc. Nursing Degree Programme } & 2 \text { years } \\ \text { M.Sc. Degree Programme } & 2 \text { years } \\ \text { Diploma in Psychiatry Health Nursing } & 1 \text { Year } \\ \text { Diploma in Renal Nursing } & 1 \text { Year } \\ \text { Diploma in Critical Care Nursing } & 1 \text { Year } \\ \text { Diploma in Emergency \& Disaster } & \\ \text { Management Nursing } & 1 \text { Year } \\ \text { Diploma in Post Basic Nursing } & 1 \text { Year }\end{array}$

Aga Khan is the only institute where Masters' degree in Nursing Sciences programme is offered to the students. It was started in 2001. Aga Khan is acknowledged as a top university in Pakistan because of its foreign affiliations.

\section{Theoretical framework for undertaking this research}

As this study focuses on the evaluation of an ESP curriculum at an institution of higher learning, the CIPP Model by Stufflebeam (2003) was chosen (Figure 1). However, this study only emphasizes on the Product Evaluation which focuses on gathering inputs or feedbacks from the students who had undergone industrial training. In addition, views from English lecturers as well as analyses of the ESP syllabus were utilized to make the process of evaluating the ESP curriculum more comprehensive. 

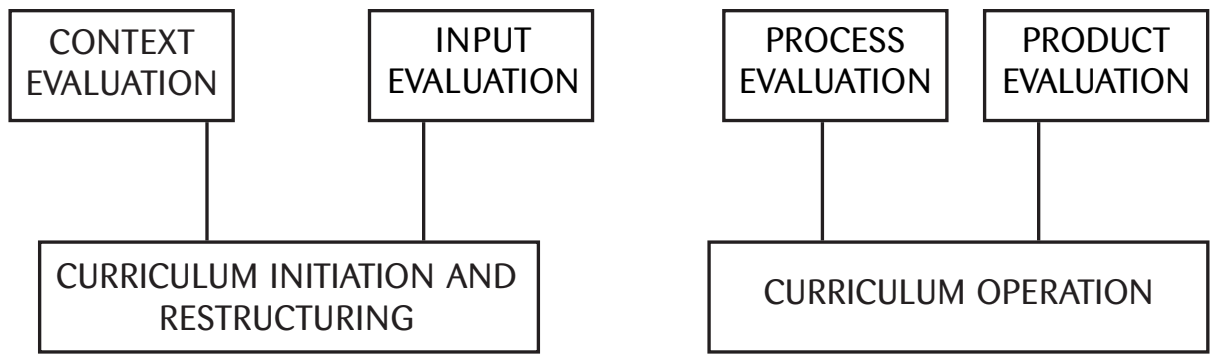

Figure 1: The framework of the CIPP model

According to Stufflebeam (2003), product evaluation "provides information for determining whether objectives are being achieved and whether the change procedure which has been employed to achieve them should be continued, modified or terminated". The BScN English language curriculum that is under scrutiny has been taught to the nursing students throughout of their educational tenure at their respective nursing institutes in Pakistan. As these students have undergone their professional training and experienced themselves the relevancy and adequacy of the ESP curriculum, knowledge that they have learnt and their evaluations of the ESP BScN course would help the curriculum panel with decision-makers that redesign the ESP course to make appropriate amendments of the existing syllabus (Alexander, Argent \& Spencer 2008).

\section{Rationale for taking instructors' perceptions of the English language}

Language instructors are selected because this group had firsthand knowledge of the learners' inadequacies. For this research, the researcher selected population of ELT practitioners from various nursing institutes. These unstructured interviews took place vis-à-vis the instructors of the nursing English courses from various institutions of health care institutes of Lahore and the researcher himself. The purpose of having these semi-structured interviews was to get knows their perceptions and perspectives of the exiting language curriculum and the requirements of the learners (Brunton, 2009). They were selected based on the criteria of having more than two years of teaching experiences at least in ESP English for Nursing Purposes to the students of the nursing programme curriculum.

\section{Thematic analysis of the interviews}

First the data was collected through semistructured interviews vis-à-vis the researcher and the nursing instructors. These interviews were transcribed and then analyzed according to thematic analysis.

\section{Theme 1: Need of English language for nurses}

All the instructors unanimously agreed on this fact that nurses need English not only to fulfill their professional but their academic requirements too. They considered English as a lingua franca of the world and an operational language all over the world. They pointed out that written skills were required for their final summative assessment annually whereas active listening followed by speaking was required considering their professional requirements. Instructor Cathy enumerates the importance in these words:

If you are good at language, then obliviously you are good at everything. So it is equally good for the nurses too because most of the time, they have to communicate with their 
health-care professionals in English, they have to communicate with doctors, they have to communicate with their managers, they have to communicate with other nurses, they have to communicate with their seniors, and they have to communicate with their teachers. So their medium of instruction is altogether is English and they have to appear for the exams in English language either they are to attempting their nursing subjects, their core subjects or their English as a subject.

\section{Theme 2: Problematic areas for nurses}

All the instructors felt that nurses had problematic areas. There were various reasons behind this factor. First nursing students came from different backgrounds both Urdu and English medium, rural and urban areas; therefore, their command over language was inadequate. Secondly these nursing students had science background and their inclination was more towards science subjects instead of language or arts. Instructor Cathy indicated that we as teachers didn't teach the language but we teach about language to our students to which instructor Aliyan also agreed. Hence the problem lay was not only with learners but also with the instructors' methodologies that caused problem for nurses.

\section{Theme 3: Irrelevancy of the syllabus}

All the instructors felt that the existing nursing course was irrelevant to nursing students' needs. There was indeed no prescribed syllabus but only a course outline which was not only irrelevant to my students' needs but also outdated as avowed by instructor Aliyan.

\section{Theme 4: Inadequacy of the course}

It was inadequate as well considering the needs of the learners because it only catered to the written skills for annual examinations. Rests of the three skills were neglected out rightly. Instructor Aliyan said:

The questions are repetitive in nature that promote route-learning amongst students of nursing.

So overall all the instructors felt the inadequacy of the course at large in align with the needs of the nursing students.

\section{Theme 5: Suggestions to improve the syllabus}

When it came to suggestions, all the instructors were kind enough to give handful of suggestions to improve the syllabus for nurses in Pakistan. The main reason behind these suggestions emanated from the fact that mostly teachers were taken onboard when it came to either designing the curriculum or making policies at examination fronts. One of the major suggestions was concerning the improvement in the existing syllabus which should have been designed keeping in mind the needs of the learners in which all nursing instructors should be kept onboard and the syllabus should be compatible to the needs of the instructors.

The instructors also portrayed the same circumstances in which nurses needed the required language command to fulfill their specific roles. They unanimously termed English language skills are the most important for nurses specially and generally across disciplines. Instructor Daneen says:

Academically they cannot prepare for their annual examination if they don't have good English. If they want to pursue their higher studies, they cannot move forward without having adequate linguistic abilities. 
Instructor Erum states:

I have observed this profession in first hand. They now acquire innumerable outstanding degrees (post RN BSN, B.S.c.N Generic Engineering, M.S.cN and even PhD Nursing). While studying all these medical subjects, they have to understand, comprehend or perceive English language so all these skills are important for sound understanding.

Overall, the students' English proficiency in all the four skills (speaking, listening, reading and writing) in the ESP $B S c N$ English for Nursing Purposes curriculum was still weak especially in speaking and writing skills. However, it also gave a fair glimpse of the English language needs of the professional nurses on basis of the English proficiency survey. It disclosed the need of speaking and writing skills for the nurses to fulfill their specific roles that they had to play as professionals at health care centers.

English language usages cause problems because speaking is the most neglected area for the instructors and students both. One of the instructors reveals that it is so because speaking skills are not given enough emphasis in our language classrooms and students are also not given ample opportunities to practice their speaking skills.

Another factor contributed to this factor is the assessment patterns that is followed and worked towards is for annual examination. In nursing examination, only written are required to take part and rest of all the skills are put aside.

Ahmed (2005) highlighted that language is not taught in context but in isolation in her study while evaluating the curriculum of Pakistan military personnel. Instructor Cathy also indicates the same issue and notes that;

We don't teach language but we teach about the language. This is the dilemma.
Responses from the English language instructors concerning the students' English proficiency validate the same scenario. They agreed that all the four skills were equally important for the students to excel in their future work place but they were more worried of the students' level of English proficiency. Although the students had put speaking skills as the most important skills that they had difficulty with, the English language lecturers indicated that the students were weak in all four skills. These judgments were based on the continuous monitoring of the students' progress during the instructional process, assigned tasks or projects, discussions as well as the annual examination carried out by UHS to the students in terms of written forms. As stated by the Instructor $\mathrm{A}$ in the interview sessions:

Nursing students have science background whose language skills are primarily inadequate overall. Their major inclination has been towards science subjects; thus language remains at the backburners usually.

Another English Language Instructor Faseeha added by saying:

When it comes to speaking, they immensely/ enormously lack confidence moreover if they wish to express themselves in some form of speech (when giving answers orally or extempore speech), nurses lack vocabulary or appropriate choice of words.

Hence English language skills are problematic areas for the nurses in which speaking and writing skills are on the top and reading and listening are somewhat in a better position. However, it is believed and also indicated by one of the instructors as well that good reading leads to good writing and good listening leads to good speaking skills.

Responses from the English language lecturers varied pertaining to the relevancy of the $\mathrm{BScN}$ English language curriculum. They consider it irrelevant to the specific 
needs of the learners. They considered that it is still relevant only to the writing skills and other three skills are neglected at the expense of one skill.

As stated by Instructor Aliyan:

That course outline is outdated but somehow relevant in many ways. However, it doesn't fulfill the criteria of learners' linguistic needs. The existing curriculum only aim to assess students' writing skills in their final examination that means it is only assesses writing skills only.

This was added by Instructor Bashir, Fasheeha and Erum:

The prescribed course is based on the concept of rote memorization; there is no creativity and various activities for student nurses in that book.

Instructor Cathy concludes in these words:

You see it should be taught under the umbrella of ESP and under the umbrella of ESP it should be taught under the umbrella of EOP instead of teaching them all the translations studies etc... so I would not suggest that our nursing students to be taught like this.

Hence the findings disclosed that the English language curriculum is relevant as far as nursing professionals are concerned but for English language instructors, they had mixed perception based on their experience with nursing teaching and having adequate knowledge of the field.

The responses of the instructors were also similar to the findings of statistical analysis of the questionnaires. Instructor Aliyan states:

It is not adequate especially when it comes to equipping students all four skills of language reading, listening, speaking, and writing. The course outline is quite obscure and doesn't define any rubrics at all. The questions are repetitive in the exams.
Instructor Bashir observes:

There is typical report writing, reading comprehension and essay writing and translation exercises which only needs to be learnt by heart and does not need any understanding in the true sense.

Whereas Instructor Cathy presents the bleaker scenario in terms of its adequacy:

There is no compatibility between nursing student's needs and the curriculum we have.

All the instructors still considered that the current course needed to be reviewed so that the students could be better prepared to meet the demands of the industry as the complaint that mostly given by the industry was that the students were lacking communication skills in English language as well as soft skills.

The part is related to nurses' evaluation of the ESP BScN English for Nursing Purposes course after they had undergone their professional training to verify whether the course was adequate in preparing them for their future work place. All six items showed that the nurses felt some aspects were needed to be added in the course to give a better impact to the students.

This finding shows that the ESP BScN English for Nursing Purposes curriculum is adequate enough to prepare the students to meet the demand of their professional settings. Although some of the students were satisfied with the content of the course and feel that the course was sufficient to train them for their future work place, they were still some others who felt that certain aspects needed to be taken into considerations such as more contact hours and communication skills activities before they were completely ready and confident enough with their ESP training. As for the English language instructors, they still felt that the ESP BScN English for Nursing Purposes course was inadequate in preparing the students for the work place. Unless the course was reviewed for the 
betterment of the students, for the moment they just have to make do with what they have and make the best out of it.

Instructor Aliyan said:

All the four skills are skills are equally important for nurses. Listening skills for professional and writing skills for academic requirements are important.

Instructor Bashir observed:

All four skills are equally significant for nurses because they work in a diverse environment and encounter real life situations. They have to read documents, talk with patients, superordinates and sub-ordinates etc, listen and answer patient queries in the wards. Therefore, nurses need to acquire all skills effectively.

Instructor Aliyan observed:

Some students are poor at listening, some are poor at speaking, some are poor at reading, some are poor at writing but majority of the nursing students are poor at listening and speaking skills.

\section{Conclusion}

The basic objective of the research was to review the existing $\mathrm{BScN}$ curriculum English for Nursing Purposes that corroborated with that of the nurses' needs and the specific roles they were required to perform at their workplace on day to day basis so that their problematic areas could be analytically identified and subsequently reported with recommendations. As a result of this study the researcher proposed the following implications as a result of the study to improve the existing standards of nursing English in Pakistan. This study aimed to evaluate the relevancy and adequacy of the BScN English language curriculum in the light of needs of the nurses.

What the researcher observed while visiting several nursing institutes of Lahore that English as a course is taught by a visiting faculty on weekly basis. So there is a dire need to establish a full-fledge English language departments with fully equipped language lab facilities. Permanent faculty should be hired to train nurses for their future professional settings. English for Nursing Purposes is a separate domain and it should be dealt accordingly by HEC/PNC in an appropriate way in which ELT and ESP exerts should be taken onboard. The suggested course should be based on the needs of the learners.

Assessment standards need to be improved. As findings reflect that there is summative assessment instead of formative assessment but the course designed is according to the demands of semester system instead of fulfilling the demands of those who appear once in a year for final assessment. Instead of having annual assessment, it should be implemented in semester system at institutional level in which language teachers should be autonomous enough to tailor the course considering the needs of the learners. Meanwhile modes of assessment should be included to assess each skill separately. Rubrics for each skill should be vividly explained either by the HEC or respective institution.

Faculty should be trained with specifically keeping in mind nursing English. Refresher courses for language teachers should be introduced in which HEC can play a pivotal role.PNS/HEC should propose a clear language mandate for nurses and all nursing institutes should be binding members to follow and implement the same mandate for nursing English in Pakistan.

Authentic material/real life situations contents should be added. Classroom should be fully resourced with tech friendly laboratories to make the language classroom more communicative oriented. Instead of utilizing the methods of students-centered or lecturer-centered teaching and learning styles, students should be taught to be more autonomous in their learning so that they would learn 
to be more independent in their learning and aware of the various choices they have to improve their English instead of depending totally on the lecturers. Lecturer's role is only to function as facilitators in helping them in their learning. This is when more hands-on activities and task-based activities could be carried out and to challenge the students to perform better. Indirectly this would train them to be autonomous and independent in preparing them for their future workplace.

\section{References}

Ahmed, N.(2005) Legal English: Acase for ESP. PhD thesis, Bahauddin Zakariya University Multan, Pakistan. Retrieved from http:/ / eprints.hec.gov.pk/

Alexander, O., Argent, S. \& Spencer, J. (2008). EAP Essentials: A teacher's guide to principles and practice. Reading: Garnet Education.

Basturkmen, H. (2006). Ideas and optionsin ESP. London: Roultedge

Brunton, M. (2009). An evaluation of students' attitudes to the general English and specific components of their course: A case study of hotel employees in Chiang Mai, Thailand. ESP World, 8 (25). Retrieved on November, 2014 from http:/ /www.esp-world.info/Articles_25/ ESP\%20world\% 20study.pdf

Dudley-Evans, T., \& St. John, M.J.(1998). Developments in ESP: Amulti disciplinary approach. Cambridge: Cambridge University Press.

Ellis, R. (1994). The study of second language acquisition. Oxford: Oxford University Press.

Flowerdew,J., \& Peacock, M. (2001). Research perspectives on English for academic purposes. Cambridge: Cambridge University Press.

Fontana, A., \& Frey, J.H. (2005). The interview: From neutral stance to political involvment. In N. K. Denzin,
\& Y.S. Lincoln (Eds.).The Sage Handbook of Qualitative Research, (pp. 695-728) ( $3^{\text {rd }}$ ed). Thousand Oaks, CA: Sage.

Hatam, A. H., \& Shafiei, S. (2012). The evaluation of the effectiveness of ESP courses in enhancing technical translation proficiency: A case study of ESP course for mechanical engineering students. English Language Teaching, 5 (5).

Johns, M. (2013). The handbook of English for speciûc purposes $\left(1^{\text {st }}\right.$ ed.). B. Paltridge \&S. Starûeld (Eds.) London. Wiley \& Sons, Inc.

Lofland, J., Snow, D., Anderson, L., \& Lofland, L.H. (2006). Analyzing social settings: A guide to qualitative observation and analysis. Canada: Thomson Wadsworth.

Robinson, P. (1991). ESP today: Apractitioner's guide. New York: Prentice Hall.

Stufflebeam, D. L. (2003). The CIPP Model for Evaluation: An update, a review of the model's development, a checklist to guide implementation. Retrieved March 2, 2015 from $h t t p: / / w w w . w m i c h . ~ e d u / e v a l c t r /$ pubs/CIPP-ModelOregon10-03.pdf

The author: Mr. Adeel Khalid is a Lecturer at the Department of English Language and Literature at Forman Christian College (A Chartered University), Lahore. He holds his M. Phil. TESL from Beaconhouse National University, Lahore. He graduated in English Literature and Political Theory from Forman Christian College and University of Punjab respectively. He has many scholarly publications in renowned international journals. His research focuses on the second language issues ranging from classroom discourse to the cultural politics of TESOL in Pakistan. 